\title{
IDENTIFIKASI METABOLIT SEKUNDER DAN BIOAKTIFITAS EKSTRAK METANOL UMBI SUWEG (Amorphophallus campanulatus B.)
}

\author{
Dewi Maimunah*, Risna Agustina, Laode Rijai \\ Laboratorium Penelitian dan Pengembangan Farmaka Tropis Fakultas Farmasi Universitas \\ Mulawarman, Samarinda, Kalimantan Timur \\ *Email : dewimaimunahfarmasi@yahoo.com
}

\begin{abstract}
ABSTRAK
Stres oksidatif merupakan salah satu penyebab penyakit degeneratif di Indonesia. Stres oksidatif adalah keadaan dimana jumlah radikal bebas lebih banyak daripada antioksidan di dalam tubuh. Umbi suweg (Amorphophallus campanulatus B.) adalah tanaman yang kaya akan kandungan flavonoid dan saponin. Dimana senyawa-senyawa tersebut telah banyak dilaporkan sebagai agen antioksidan. Hal ini melatarbelakangi peneliti untuk mengidentifikasi kandungan metabolit sekunder dalam ekstrak metanol umbi suweg dan uji daya antioksidan dalam ekstrak metanol umbi suweg secara kualitatif. Identifikasi metabolit sekunder dilakukan secara kualitatif yaitu metode uji tabung dengan pereaksi tetes dan menggunakan metode lempeng KLT dengan pereaksi semprot. Uji daya antioksidan seraca kualitatif dilakukan pada lempeng KLT dengan pereaksi semprot 0,008\% DPPH dalam metanol. Identifikasi metabolit sekunder dan uji aktifitas antioksidan menggunakan metode Kromatografi Lapis Tipis (KLT) terhadap ekstrak metanol umbi suweg menunjukkan adanya flavonoid, alkaloid, saponin, dan terpenoid, serta aktivitas antioksidan.
\end{abstract}

Kata Kunci: Metabolit sekunder, antioksidan, Amorphophallus campanulatus

\begin{abstract}
Oxidative stress is the one that causes degenerative illness in Indonesia. Oxidative stress is a condition when free radical in human body is higher than antioxidant. Suweg tuber (Amorphophallus campanulatus B.) is plant that rich of flavonoid and saponin. Where that compounds has been widely reported as antioxidant agent. It is behind the researchers to identify the content of secondary metabolites of Suweg tuber metanol extract and identify the antioxidant activity of Suweg tuber metanol extract qualitatively. Identification of secondary metabolites conducted qualitative test tube with reagent drops method and using Thin Layer Chromatography (TCL)method. Testing antioxidant activity using qualitative methode using Thin Layer Chromatography (TCL) with spray reagent $0.008 \%$ DPPH in methanol. Identification of secondary metabolites and testing of antioxidant activity using Thin Layer Chromatography (TCL) method of extract metanol form suweg tuber showed the presence of secondary metabolites such as flavonoid, alkaloid, saponin and terpenoids, and an activity as antioxidant.
\end{abstract}

Key Word: Secondary metabolites, antioxidant, Amorphophallus campanulatus 


\section{PENDAHULUAN}

Metabolit Sekunder adalah senyawa metabolit yang tidak esensial bagi pertumbuhan organisme dan ditemukan dalm bentuk yang unik atau berbeda-beda antara spesies yang satu dan yang lainnya fungsi metabolit sekunder adalah untuk mempertahankan diri dari kondisi lingkungan yang kurang menguntungkan, misalnya untuk mengatasi hama dan penyakit, menarik polinator, dan sebagai molekul sinyal. (Rasyid,2012). Beberapa senyawa metabolit sekunder memiliki aktivitas sebagai antioksidan. Antioksidan merupakan senyawa yang dapat menghambat reaksi radikal bebas dalam tubuh. Tanaman suweg di dalam taksonomi tumbuh-tumbuhan diklasifikasikan dalam Divisi Spermatophyta, Kelas Monocotiledonae, Famili Araceae, Genus Amorphophallus dan Spesies Amorphophallus campanulatus BI (Hariana, 2006).

Suweg kaya kandungan kimia seperti flavonoid dan saponin pada umbi. Sementara batang dan daun mengandung saponin dan polifenol. Anggota famili Araceae itu bersifat antiinflamasi, antiracun, mencegah pendarahan, dan mengobati luka (Hariana, 2006).

Ekstraksi merupakan proses pemisahan bahan dari campurannya dengan menggunakan pelarut. Ekstrak adalah sediaan yang diperoleh dengan cara ekstraksi tanaman obat dengan ukuran partikel tertentu dan menggunakan medium pengekstraksi (menstrum) yang tertentu (Agoes, 2007).

Maserasi merupakan cara penyarian yang sederhana. Maserasi dilakukan dengan cara merendam serbuk simplisia dalam cairan penyari. Cairan penyari akan menembus dinding sel dan akan masuk dalam rongga sel yang mengandung zat aktif. Zat aktif akan larut dan karena adanya perbedaan konsentrasi antara larutan zat aktif di dalam sel dengan yang diluar sel, maka larutan yang terpekat didesak keluar (Voight,1994). DPPH (1,1Diphenyl-2-picrylhydrazyl) merupakan suatu molekul radikal bebas dengan warna ungu dapat menjadi seyawa stabil dengan warna kuning oleh reaksi dengan antioksidan, dimana antioksidan memberikan satu elektronnya pada DPPH sehingga terjadi peredaman pada radikal bebas DPPH (Yuhernita, 2011)

Tujuan penelitian ini adalah untuk mengidentifikasi metabolit sekunder dan aktivitas antioksidan ekstrak metanol umbi suweg terhadap DPPH.

\section{METODE PENELITIAN}

\section{Bahan}

Bahan sampel yang digunakan dalam penelitian ini adalah umbi suweg yang diambil dari daerah Bontang Kalimantan Timur. Bahan penyari adalah metanol. Eluen yang digunakan adalah kloroform dan metanol. Bahan kimia lainnya adalah DPPH $0,008 \%$, asam fosfat $86 \%$, pereaksi Dregendorff dan Meyer, Timbal asetat 25\%, sitroborat, Asam oksalat 0,3\%, aquades, $\mathrm{HCl} 2 \%, \mathrm{HCl} \mathrm{10 \% ,} \mathrm{FeCl}_{3}$, Pita $\mathrm{Mg}$, Metanol 95\%, asam asetat anhidrat, $\mathrm{H}_{2} \mathrm{SO}_{4}$.

\section{Alat}

Peralatan yang digunakan dalam penelitian ini antara lain timbangan analitik, gelas kimia, rotary evaporator, Labu ukur $25 \mathrm{ml}$, mikro pipet 100-1000 $\mu \mathrm{L}$, chamber, lempeng KLT, pipet tetes, tabung reaksi, rak tabung, Lampu UV 366 dan 254, hot plate, corong penyaring, Pipet Ukur $5 \mathrm{ml}$. alumunium foil, kertas saring, alat penyemprot.

\section{PROSEDUR PENELITIAN}

\section{Pengumpulan Sampel}

Umbi suweg didapatkan di daerah Bontang Kalimantan Timur. Umbi tersebut kemudian di sortasi basah untuk memisahkan kotorannya dan ditimbang. Kemudian dicuci 
menggunakan air mengalir dan dikeringkan dengan cara diangin-anginkan tanpa terpapar langsung dengan sinar matahari. Umbi yang kering itu kemudian di sortasi kering dan dipotong kecil-kecil. Simplisia umbi suweg siap digunakan.

\section{Ekstraksi}

Simplisia umbi suweg di maserasi dengan menggunakan pelarut metanol selama \pm 3 hari , dilakukan pengadukan dan penggantian pelarut. Maserat (hasil maserasi) di dapatkan dengan cara disaring menggunakan kertas saring . maserat tersebut kemudian di uapkan pelarutnya dengan rotary evaporator dan dilanjutkan dengan menggunakan water bath untuk mendapatkan ekstrak kental metanol.

\section{Pembuatan Larutan DPPH 0,008\%}

Ditimbang DPPH seberat $2 \mathrm{mg}$ kemudian dilarutkan dalam $25 \mathrm{ml}$ metanol. Sehingga didapatkan larutan dengan konsentrasi 0.008\%. larutan DPPH dijaga agar tetap dalam suhu rendah dan dalam keadaan terlindung dari cahaya.

\section{Pengujian Metabolit Sekunder}

Pengujian ini dilakukan secara kualitatif dengan dua metode, yaitu metode tabung dengan pereaksi yang di teteskan dan juga dengan metode Kromatografi Lapis Tipis dengan menggunakan pereaksi yang di semprotkan. Metabolit sekunder yang di identifikasi meliputi flavonoid, alkaloid, steroid, terpenoid, saponin, fenol, dan asam aromatis.

\section{Pengujian Metabolit Sekunder dengan Metode Tabung}

Sebanyak $2 \mathrm{~mL}$ larutan ekstrak diletakkan dalam tabung reaksi kemudian di tambahkan dengan masing-masing pereaksi yang sesuai.

\section{Pengujian Metabolit Sekunder dengan Metode Kromatografi Lapis Tipis}

Sampel di totolkan pada lempeng KLT kemudian di elusi dengan pengelusi terbaik. Pengelusi terbaik pada penelitian ini adalah metanol : klorofom dengan perbandingan 9:1. Dikatakan terbaik karna pada perbandingan ini mendapatkan hasil pemisahan yang terbaik dan tidak terlalu menumpuk diatas atau dibawah.

\section{Pengujian aktivitas Antioksidan}

Pengujian ini dilakukan secara kualitatif dengan metode Kromatografi Lapis Tipis (KLT) terhadap DPPH 0,008\% yang di semprotkan. Eluen yang digunakan adalah metanol : klorofom (9:1). Timbulnya noda kuning keputih-putihan selama 30 menit menunjukkan positif antioksidan (Marliana,2007) Uji DPPH merupakan metode yang mudah untuk menapis sejumlah kecil molekul antioksidan karena reaksi dapat diamati secara visual menggunakan KLT (Yuhernita, 2011) .

\section{HASIL PENELITIAN}

Pada pengujian metabolit sekunder dengan menggunakan metode tabung dengan pereaksi tetes menunjukkan bahwa ekstrak metanol umbi suweg mengandung alkaloid, saponin, dan fenol. Sedangkan pada metode kromatografi lapis tipis menunjukkan bahwa ekstrak metanol umbi suweg mengandung steroid, flavonoid, dan alkaloid.

Perbedaan hasil pada kedua metode tersebut kemungkinan dapat disebakan oleh pereaksi dan tingkat ketelitian dari masing-masing metode. Metode KLT dirasa lebih efisien karena hanya membutuhkan sedikit sampel untuk dapat mengidentifikasi suatu metabolit sekunder tertentu. 
Tabel 1. Hasil Identifikasi Metabolit Sekunder Metode Tabung

\begin{tabular}{cc}
\hline Jenis Identifikasi & Keterangan \\
\hline Flavonoid & - \\
Steroid & - \\
Alkaloid & + \\
Saponin & + \\
Fenol & + \\
\hline
\end{tabular}

Tabel 2. Hasil Identifikasi Metabolit Sekunder Metode KLT

\begin{tabular}{|c|c|c|c|}
\hline Jenis Identifikasi & Pereaksi & $\begin{array}{l}\text { Setelah Diberi } \\
\text { Pereaksi }\end{array}$ & Keterangan \\
\hline Terpenoid & $\begin{array}{c}\text { Dipanaskan pada } \\
\text { suhu } 100^{\circ} \mathrm{C} \text { selama } 10 \\
\text { menit }\end{array}$ & $\begin{array}{l}\text { Berpendar pada UV } \\
366 \text { setelah pemanasan }\end{array}$ & + \\
\hline Steroid & $\begin{array}{c}\text { Asam fosfat } 85 \% \\
\text { Dipanaskan } 120^{\circ} \mathrm{C} \\
\text { selama } 15-30 \text { menit }\end{array}$ & $\begin{array}{l}\text { Berpendar pada UV } \\
366\end{array}$ & - \\
\hline Alkaloid & Dragendroff & $\begin{array}{c}\text { Noda jingga coklat } \\
\text { pada plat }\end{array}$ & + \\
\hline \multirow{2}{*}{ Flavonoid } & Timbal asetat $25 \%$ & $\begin{array}{c}\text { Berpendar pada UV } \\
366\end{array}$ & + \\
\hline & Sitroborat & $\begin{array}{c}\text { Berflourosensi hijau- } \\
\text { kuning }\end{array}$ & + \\
\hline Asam aromatis & $\mathrm{H}_{2} \mathrm{O}_{2}$ & $\begin{array}{l}\text { Bercak flourosensi biru } \\
\text { pada UV } 366\end{array}$ & - \\
\hline
\end{tabular}

Pada pengujian aktivitas antioksidan ini ekstrak metanol umbi suweg menunjukkan reaksi positif dengan adanya bercak noda berwarna kuning keputih-putihan dengan warna latarbelakang ungu pada sinar tampak. Bercak noda kuning keputih-putihan ini menunjukkan adanya reaksi peredaman DPPH oleh senyawa metabolit sekunder yang terdapat dalam ekstrak. Adanya aktivitas antioksidan dapat dilihat dari Gambar1.

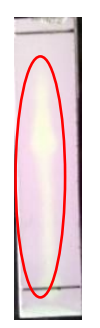

Gambar 1. Hasil pengujian aktifitas antioksidan terhadap ekstrak metanol umbi suweg pada sinar tampak setelah disemprotkan DPPH 0,008\%. Lingkaran merah menunjukkan spot aktif yang beraktivitas antioksidan. 
Dari gambar diatas dapat diketahui bahwa ekstrak umbi suweg memiliki aktivitas antioksidan. aktvitas antioksidan ini disebabkan oleh kandungan metabolit sekunder yang terdapat di dalam ekstrak. Senyawa Alkaloid dan flavonoid adalah salah satu senyawa metabolit sekunder yag memiliki aktifitas antioksidan. sifat antioksidan dari flavonoid berasal dari kemampuan untuk mentransfer sebuah elektron ke senyawa radikal bebas dan juga membentuk kompleks dengan logam. Senyawa alkaloid lain yang memiliki aktivitas antioksidan adalah quinolon, kafein, yang dapat meredam radikal hidroksil. Hanya saja dalam penelitian ini kemungkinan bukan hanya alkaloid dan flavonoid saja yang berperan dalam aktivitas antioksidan ini, karna pada lempeng KLT masih banyak senyawa yang bertumpuk, bukan merupakan senyawa tunggal.

\section{KESIMPULAN}

Kandungan senyawa metabolit sekunder ekstrak metanol umbi suweg yang teridentifikasi adalah alkaloid, saponin, fenol, terpenoid, alkaloid, flavonoid. Ekstrak metanol umbi suweg memiliki aktivitas sebagai antioksidan.

\section{DAFTAR PUSTAKA}

Agoes, G. 2007. Teknologi Bahan Alam. Penerbit ITB. Bandung.

Hariana A. 2006. Tumbuhan Obat dan Khasiatnya Seri 3. Penerbit Swadaya. Jakarta.

Marliana, eva. 2007. Analisis Senyawa Metabolit Sekunder dari Batang Spatholobus ferrugineus (Zoll\&Moritzi) Benth yang Berfungsi sebagai Antioksidan. Jurnal Penelitian Mipa Vol.1 No.1

Rasyid, Abdullah. 2012. Identifikasi Senyawa Metabolit Sekunder-Serta Uji Aktifitas Antibakteri dan Antioksidan Ekstrakn Metanol Teripang Stichopus hermanii. Jurnal Ilmu dan Teknologi Kelautan Tropis. Vol. 4. No. 2. Hlm. 360-368.

Yuhernita, 2011. Analisis Senyawa Metabolit Sekunder dari Ekstrak Metanol Daun Surian yang Berpotensi Sebagai Antioksidan. Maraka, Sains. Vol. 15. No. 1. hal 48-52 